5 - ORIGINAL ARTICLE

ISCHEMIA-REPERFUSION

\title{
Effect of hyperbaric hepatic hyperoxia on the liver of rats submitted to intermittent ischemia/reperfusion injury ${ }^{1}$
}

\author{
Diego Elias da Silva CaldeiraI, Marina Rodrigues Garcia da Silveira ${ }^{\mathrm{II}}$, Maria Rita Rodrigues Alves Margarido ${ }^{\mathrm{II}}$, José Carlos \\ Vanni"II, Omar Feres ${ }^{\text {III }}$, Orlando Castro e Silva ${ }^{\text {III }}$ \\ DOI: http://dx.doi.org/10.1590/S0102-86502014001300005 \\ IFaculty of Medicine of Marília, FAMEMA, Marília, São Paulo, Brasil. Data collection and analysis. \\ IRibeirão Preto Medical School, FMRP, Ribeirão Preto, São Paulo, Brasil. Data collection and analysis. \\ IIILiver Transplantation Unit, Department of Surgery and Anatomy, Ribeirão Preto Medical School - University of São Paulo, Brazil. Critical Review; \\ Responsible for English language.
}

\begin{abstract}
PURPOSE: To determine the effect of hyperbaric hyperoxia as hepatic preconditioning on hepatocellular integrity in rats submitted to intermittent hepatic ischemia/reperfusion injury.

METHODS: Twenty male Wistar rats were divided into 4 groups (SHAM, I/R, HBO-I/R and CONTROL). The surgical technique consisted of total clamping of the hepatic pedicle for $15 \mathrm{~min}$, followed by reperfusion for $5 \mathrm{~min}$, performed twice. The application of hyperbaric oxygen (HBO) was carried out in a collective chamber (simultaneous exposure of 4 rats) pressurized directly with oxygen at 2 ATA for $60 \mathrm{~min}$. Tissue malondialdehyde (MDA) levels were determined and blood samples were collected for the determination of serum AST and ALT levels. Data were analyzed statistically by the Mann-Whitney test, with the level of significance set at $p<0.05$. RESULTS: A statistically significant difference in MDA $(\mathrm{p}<0.05)$ was observed between control and HBO-I/R, but not between control and I/R. Regarding AST, there was a difference between control and I/R and HBO-I/R. Analysis of ALT revealed a significant difference between control and $\mathrm{I} / \mathrm{R}(\mathrm{p}<0.05)$ and between $\mathrm{I} / \mathrm{R}$ and HBO-I/R, with no difference between control and HBO-IR.
\end{abstract}

CONCLUSION: Hyperoxic preconditioning proved to be favorable regarding alanine transaminase, but not aspartate aminotranserase or malondialdehyde levels.

Key words: Hyperbaric Oxygenation. Liver. Ischemia. Reperfusion. Lipid Peroxidation. Rats. 


\section{Introduction}

In hepatic ischemia/reperfusion (I/R), hepatic damage occurs by temporary deprivation of blood flow to the liver, as observed in hepatectomy, liver transplantation and hemorrhagic shock, with consequent effects ranging from a slight increase in serum levels of the hepatocellular enzymes aspartate aminotranserase (AST) and alanine transaminase (ALT) to acute liver failure. During the period of ischemia followed by reperfusion there is a complex interaction among microvascular changes, the release of inflammatory mediators, reactive oxygen species (ROS), and neutrophil, platelet, Kupffer cell and sinusoidal endothelial cell activation ${ }^{1-7}$. As blood flow to the injured organ is reestablished, the injury suffered during the period of ischemia is aggravated. Oxidative phosphorylation is a process severely affected by reperfusion; since the respiratory chain is located on the inner mitochondrial membrane and is an important target of the injury caused by ROS originated during the period of reperfusion, it is natural to assume that a change in mitochondrial membrane permeability will result in impairment of oxidative phosphorylation. On this basis, a mitochondrial permeability transition occurs, characterized by a nonselective increase in the permeability of the inner mitochondrial membrane followed by osmotic swelling ${ }^{5,8-10}$.

Aminotransferases are intracellular enzymes that catalyze the reversible transfer of an alpha-amino group from an amino acid to an alpha-ketoacid, with the formation of new alpha-amines and alpha-ketoacids. ALT and AST are enzymes synthesized in the liver, kidney, cardiac and skeletal muscle, brain and pancreas. AST is mainly cytoplasmic and, at a lower concentration, mitochondrial, whileALT is exclusively cytoplasmic, with its values being indicators of hepatocellular integrity. Thus, serum ALT level is associated with acute hepatocellular involvement, its biochemical determination is of high diagnostic and prognostic value and changes in its serum levels are related to organic dysfunction ${ }^{4,11}$. The effect of hyperbaric oxygen therapy (HBO) on $\mathrm{I} / \mathrm{R}$ is a matter of controversy due to the lack of basic research aiming at the determination of its mechanism of action. In a previous study by our group we showed that hyperbaric pre-conditioning did not improve significantly hepatic mitochondrial function after $I / R^{9,10,12}$. Thus, in the present study we investigated experimentally whether $\mathrm{HBO}$ used as preconditioning might prevent hypoxic hepatic suffering by attenuating the injury caused by intermittent ischemia.

\section{Methods}

Research approved by the Ethics Committee for Animal Experimentation of FMRP-USP.
Twenty male Wistar rats weighing 250 to $300 \mathrm{~g}$ were divided into four groups of 5 animals each as follows: SHAM rats submitted to surgical and anesthetic stress without exposure to $\mathrm{HBO}$ and without hepatic pedicle clamping during the same I/R period as a quality control of the mitochondrial respiration assay; $\mathrm{I} / \mathrm{R}$ - rats twice submitted to $15 \mathrm{~min}$ of ischemia followed by $5 \mathrm{~min}$ of reperfusion without exposure to $\mathrm{HBO}$ (40 $\mathrm{min}$ ); HBO-I/R rats submitted to $60 \mathrm{~min}$ of $\mathrm{HBO}$ at 2 absolute atmospheres (ATA) immediately followed by two periods of $15 \mathrm{~min}$ of ischemia and 5 min of reperfusion (40 min); control - rats submitted to immediate blood and hepatic tissue collection without I/R and HBO.

The rats were housed in the animal facilities of FMRPUSP at room temperature, with a sleep-wakefulness cycle of $12 \mathrm{~h}$ and with free access to laboratory ration (Purina Nutrimentos Ltda.) and water.

\section{Surgical technique}

The animals were anesthetized intramuscularly with 20 $\mathrm{mg} / \mathrm{ml}$ solution of xylazine hydrochloride and a $50 \mathrm{mg} / \mathrm{ml}$ solution of ketamine hydrochloride at a 1:2 proportion of $100 \mathrm{mg} / \mathrm{kg} /$ weight. The surgical procedure started with a median laparotomy extending from the lower third of the xiphoid appendix to the pubis, followed by exploration of the abdominal cavity, delicate dissection of the round ligament of the liver and identification and exposure of the hepatic pedicle. The pedicle was twice fully clamped with a home-made clamp for $15 \mathrm{~min}$, followed by $5 \mathrm{~min}$ of reperfusion (declamping), for a total cycle of $40 \mathrm{~min}$. The animal was sacrificed by total exsanguination by puncture of the inferior vena cava after its exposure by manipulation of the abdominal viscera ${ }^{12}$.

$\mathrm{HBO}$ was performed in a collective chamber (simultaneous exposure of 5 rats) (Sechrist, model 2500 B) directly pressurized with oxygen. Each session lasted $60 \mathrm{~min}, 15$ of which were devoted to compression and 15 to decompression inside the chamber, with the animals thus being submitted to 30 uninterrupted min of $\mathrm{HBO}$ at $2 \mathrm{ATA}^{9,10}$. Presurgical exposure to $\mathrm{HBO}$ and all surgical procedures were always performed during the same period of the day.

\section{Determination of tissue malondialdehyde (MDA)}

MDA was determined by a colorimetric method based on reaction with thiobarbituric acid at $532 \mathrm{~nm}$ using a Versamax microplate reader (Molecular Devices) and 1,1,3,3-tetramethoxypropane ( 0 to $100 \mu \mathrm{m}$ ) as the standard. The results obtained are reported as $\mu \mathrm{M} / \mathrm{mg}$ protein $^{13}$. 


\section{Determination of serum AST and ALT}

AST and ALT were determined by a kinetic method using a CELM spectrophotometer at $340 \mathrm{~nm}$. The results are reported as $\mathrm{U} / \mathrm{L}^{4,14}$.

\section{Statistical analysis}

Data were analyzed statistically by the nonparametric Mann-Whitney test, with the level of significance set at $5 \%$ or less $(\mathrm{p}<0.05)$, using the GraphPad Prism 5 software (GraphPad Software Inc, CA).

\section{Results}

Regarding MDA levels, the control group differed significantly $(\mathrm{p}<0.05)$ from the HBO-IR but not from the I/R group $(p>0.05)$. There was no difference between the I/R and HBO-IR groups ( $\mathrm{p}>0.05$ ) or between the control and Sham groups (Figure 1).

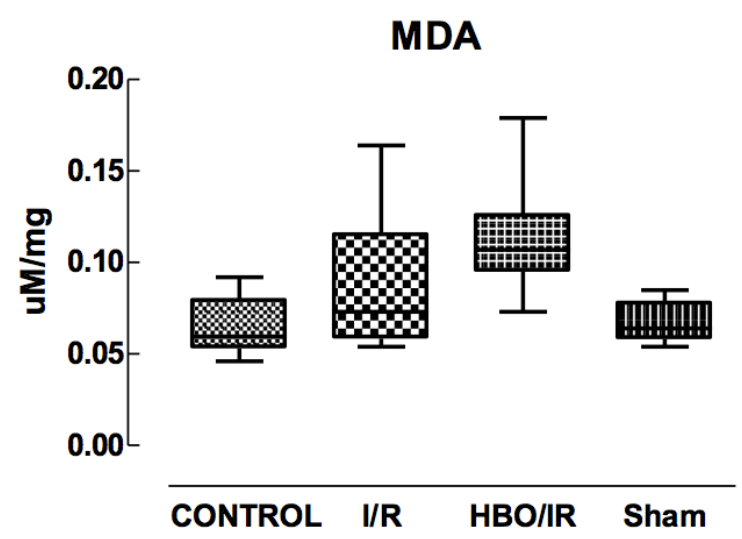

FIGURE 1 - Tissue levels of malondialdehyde (MDA): control (rats submitted to immediate blood and hepatic tissue collection without I/R or HBO). I/R (rats twice submitted to $15 \mathrm{~min}$ of ischemia followed by $5 \mathrm{~min}$ of reperfusion (40 $\mathrm{min}$ ), without exposure to $\mathrm{HBO}$ ). HBO-I/R (rats submitted to $60 \mathrm{~min}$ of $\mathrm{HBO}$ at 2 absolute atmospheres and then immediately submitted twice to $15 \mathrm{~min}$ of ischemia followed by $5 \mathrm{~min}$ of reperfusion (40 min). Sham (rats submitted to surgical stress without exposure to $\mathrm{HBO}$ and without clamping of the hepatic pedicle for $40 \mathrm{~min}$ ). Control vs I/R ( $>0.05)$, control vs HBO-IR $(p<0.05)$, control vs Sham $(p>0.05)$, I/R vs HBO-IR ( $>005)$, Sham vs I/R $(p>0.05)$, and Sham vs HBO-IR $(\mathrm{p}<0.05)$.

Regarding AST, the control group differed significantly from the I/R and HBO-IR groups $(\mathrm{p}<0.05)$. There was no difference between the control and Sham groups $(p>0.05)$ or between the I/R and HBO-I/R groups $(\mathrm{p}>0.05)$ and between the Sham and I/R and HBO-I/R groups ( $>0.05$ ) (Figure 2 ).

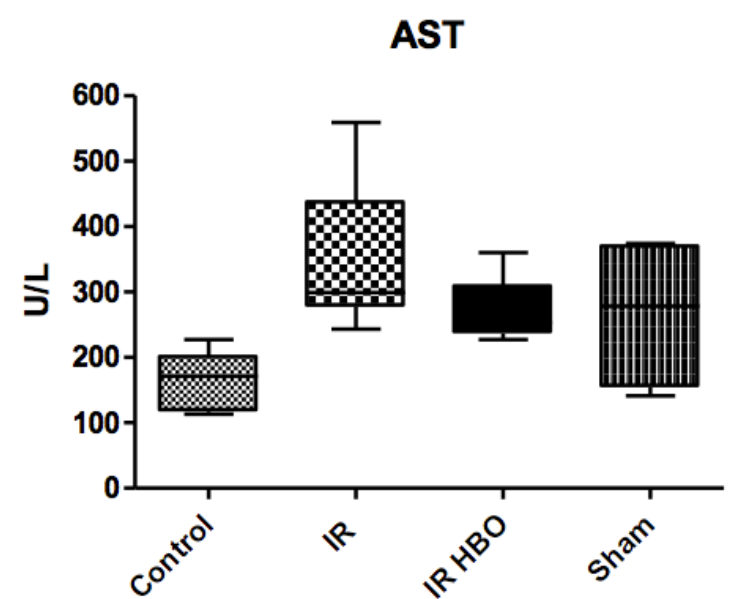

FIGURE 2 - Tissue levels of aspartate aminotransferase (AST). Control (rats submitted to immediate blood and hepatic tissue collection without $\mathrm{I} / \mathrm{R}$ or HBO). I/R (rats twice submitted to $15 \mathrm{~min}$ of ischemia followed by $5 \mathrm{~min}$ of reperfusion (40 $\mathrm{min}$ ), without exposure to $\mathrm{HBO}$ ). $\mathrm{HBO}-\mathrm{I} / \mathrm{R}$ (rats submitted to $60 \mathrm{~min}$ of $\mathrm{HBO}$ at 2 absolute atmospheres and then immediately submitted twice to $15 \mathrm{~min}$ of ischemia followed by $5 \mathrm{~min}$ of reperfusion (40 $\mathrm{min}$ ). Sham (rats submitted to surgical stress without exposure to $\mathrm{HBO}$ and without clamping of the hepatic pedicle for $40 \mathrm{~min}$ ). Control vs I/R and HBO-IR ( $p<0.05)$, Control vs Sham ( $p>0.05)$, I/R vs HBO-IR ( $>>0.05)$, Sham vs I/R and HBO-IR( $p>0.05)$.

Analysis of ALT revealed a significant difference between the control and I/R groups $(p<0.05)$ but not between the control and HBO$\mathrm{I} / \mathrm{R}$ groups ( $\mathrm{p}>0.05$ ). There was no difference between the control and Sham groups ( $p>0.05)$, but there was a difference between the I/R and HBO-I/R groups $(p<0.05)$. There was no significant difference between the Sham and I/R or HBO-I/R groups ( $\mathrm{p}>0.05$ ) (Figure 3 ).

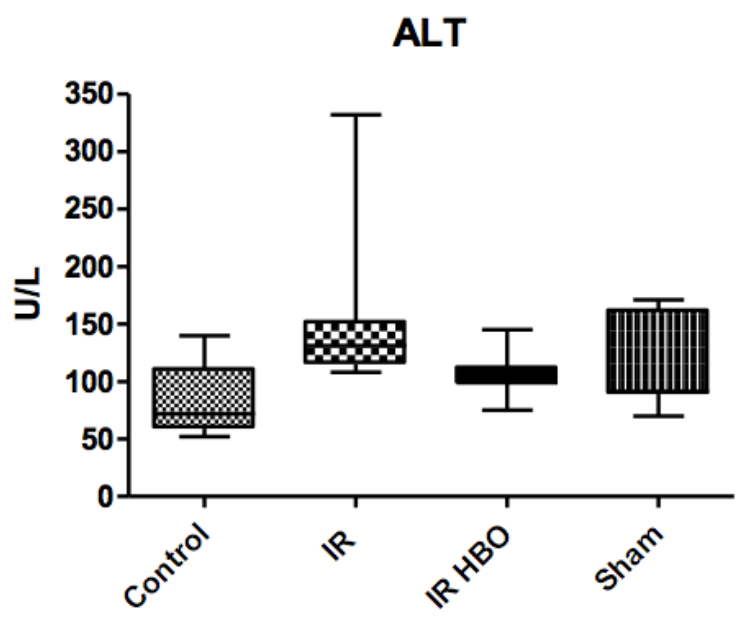

FIGURE 3 - Tissue levels of alanine aminotransferase (ALT). Control (rats submitted to immediate blood and hepatic tissue collection without $\mathrm{I} / \mathrm{R}$ or HBO). I/R (rats twice submitted to $15 \mathrm{~min}$ of ischemia followed by $5 \mathrm{~min}$ of reperfusion (40 $\mathrm{min}$ ), without exposure to HBO). $\mathrm{HBO}-\mathrm{I} / \mathrm{R}$ (rats submitted to $60 \mathrm{~min}$ of $\mathrm{HBO}$ at 2 absolute atmospheres and then immediately submitted twice to $15 \mathrm{~min}$ of ischemia followed by $5 \mathrm{~min}$ of reperfusion (40 $\mathrm{min}$ ). Sham (rats submitted to surgical stress without exposure to $\mathrm{HBO}$ and without clamping of the hepatic pedicle for $40 \mathrm{~min}$ ). control vs I/R $(p<0.05)$, control vs HBO-IR ( $>>0.05)$, Control vs Sham $(\mathrm{p}>0.05), \mathrm{I} / \mathrm{R}$ vs HBO-IR $(\mathrm{p}<0.05)$, Sham vs I/R and HBO-IR( $p>0.05)$. 


\section{Discussion}

Hepatic I/R injury has been extensively studied in the literature using serum and tissue indicators ${ }^{5,12,15,16}$. Regarding mitochondrial function, some studies have shown beneficial and protective effects of HBO therapy in the rat liver, although others have not demonstrated this efficacy ${ }^{9,10,17}$. Some authors have stated that exposure to a higher pressure increases oxygen content in plasma and in body tissues, possibly normalizing oxygen levels in the ischemic tissues. This has led to questioning whether the oxygen made available by the chamber would be utilized to aggravate the injury by providing a geater substrate for the formation of free radicals or whether this normalization would contribute to mitochondrial and tissue homeostasis. It was first thought that HBO migh exacerbate the injury, increasing the oxygen supply to the organism, with an increased production of free radicals. Although experimental studies on rats submitted to $\mathrm{I} / \mathrm{R}$ have demonstrated the beneficial effects of HBO during reperfusion, there is no consensus in the literature ${ }^{9,10,17,18}$. In the present study, with respect to MDA, we observed a tendency to an increase of ROS in the I/R group, which was aggravated in the HBO-I/R group, demonstrating a lack of protection, as also reported in other studies ${ }^{9,10,19}$.

The absolute serum levels of ALT and AST and/or the ALT/AST ratio may serve as indicators of hepatocellular integrity, with an association between the increased serum levels of these enzymes and acute liver involvement ${ }^{4}$. No significant improvement occurred in AST levels, with no significant difference between the groups submitted or not to HBO, and with the levels of both groups being higher than those of the control group. This leads us to question the hepatoprotective effect of hyperoxic preconditioning, which is supported by some authors and contested by others ${ }^{9,10,19,20}$.

ALT levels differed significantly between the control and $\mathrm{I} / \mathrm{R}$ groups, indicating an increase in the enzyme in nonpreconditioned tissue, whereas HBO-preconditioned tissue was protected by the procedure. In agreement with other literature reports, the present study demonstrates that hyperoxic preconditioning has a hepatoprotective effect, reducing the total levels of this enzyme in the HBO-I/R group to levels similar to those of the control group. This protective effect on ALT levels agrees with the results of osmotic mitochondrial swelling, with a reduction of mitochondrial edema observed in the groups submitted to preconditioning in a previous study ${ }^{9,10}$.

These results are scientifically conflicting since some authors have suggested that the combination of $\mathrm{HBO}$ and $\mathrm{I} / \mathrm{R}$ is positive while others consider it to be negative. These data suggest that, during the initial phase of I/R injury, which occurs immediately after reperfusion, hyperoxia attenuates the damage of the I/R process regarding ALT. The different findings for AST and ALT may be explained by the specificity of ALT in hepatic tissue. The increase in serum AST may occur due to surgical exposure and its harmful repercussions on skeletal tissue and on cardiac/hemodynamic factors, for example, during the experimental procedure ${ }^{21-23}$.

The two five minute periods of reperfusion studied were probably insufficient for the occurrence of an effective hyperoxic preconditioning and therefore they did not prevent hepatocellular damage, except for ALT, which was present in acceptable levels close to those of the control group. Although studies involving continuous, non-intermittent, I/R injury have shown that hyperbaric preconditioning improves hepatic mitochondrial function and reduces the serum markers of liver injury in the $\mathrm{I} / \mathrm{R}$ process, it is known that repeated $\mathrm{I} / \mathrm{R}$ episodes can be more harmful than continuous ischemia ${ }^{24}$.

Thus, we suggest that the procedure of intermittent $\mathrm{I} / \mathrm{R}$, by being more damaging, did not permit $\mathrm{HBO}$ to be equally effective, except for the ALT enzyme, which showed significant improvement in the group submitted to HBO. We believe that further studies regarding the generation of ROS and the production of nitric oxide might complement the elucidation of the possible causes of this difference.

\section{Conclusion}

Hyperoxic preconditioning proved to be favorable regarding alanine transaminase, but not aspartate aminotranserase or malondialdehyde levels.

\section{References}

1. Tibbles PM, Edelsberg JS. Hyperbaric oxygen therapy. N Engl J Med.1996;334(25):1642-8.

2. Gurdoi F, Cimsit M, Oner-Lyidogan Y, Korpinar S, Yalçinkaya S, Koçak H. Early and late effects of hyperbaric oxygen treatment on oxidative stress parameters in diabetic patients. Physiol Res. 2008;57(1):41-7.

3. Ohkawa H, Ohishi N, Yagi K. Assay for lipid peroxides in animal tissues by thiobarbituric acid reaction. Anal Biochem. 1979;95(2):351-8.

4. Giannini EG, Testa T, Savarino V. Liver enzyme alteration: a guide for clinicians. CMAJ. 2005;172(3) 367-79.

5. Rosique RG1, Rosique MJ, Rosique IA, Tirapelli LF, Castro e Silva O Jr, dos Santos JS, Evora. Effect of methylene blue on the hemodynamic instability resulting from liver ischemia and reperfusion in rabbits. Transplant. Proc 2011;43(10):3643-51.

6. Cardoso N, Silva T, Cagnolati D, Freitas T, Mente ED, Basile-Filho A, Castro e Silva O. Can joint analysis of postoperative MELD, base excess and blood lactate levels be used as an index of postoperative 
outcome for patients submitted to liver transplantation? Acta Cir Bras. 2013;28(1):54-60.

7. Cardoso NM, Silva T, Basile-Filho A, Mente ED, Castro-e-Silva O. A new formula as a predictive score of post-liver transplantation outcome: Postoperative MELD-Lactate. Transplant Proc. 2014;46(5):1407-12.

8. Augusto VS, Rodrigues AJ, Reis GS, Silveira AP, de Castro E Silva O Jr, Mente ED, Jordão AA Jr, Evora PR. Evaluation of oxidative stress in the late postoperative stage of liver transplantation. Transplant Proc. 2014;46(5):1453-7.

9. Caldeira DE, Souza ME, Gomes MC, Picinato MA, Fina CF, Feres O, Castro e Silva O. Effects of hyperbaric oxygen (HBO), as preconditioning in liver of rats submitted to periodic liver ischemia/ reperfusion, Acta Cir Bras. 2013;28(1):66-71.

10. Losada DM, Souza MEJ, Gomes MCJ, Picinato MANC, Fina CF, Feres O, Castro-e-Silva O. Hyperbaric oxygen therapy and ischemia and reperfusion: a valuable association to attenuate ischemic lesion and hepatic reperfusion. Acta Cir Bras. 2013;28(2):126-30.

11. Castro-e-Silva O, Mente ED, Sankarankutty AK, Souza MEJ, Gomes MCJ, Picinato MANC, Fina CF, Lopes JR. Biochemical liver function after partial hepatic resection with or without partial hepatic vascular exclusion. Acta Cir Bras. 2011;26:120-4.

12. Centurion SA, Centurion LM, Souza ME, Gomes MC, Sankarankutty AK, Mente ED, Castro e Silva O. Effects of ischemic liver preconditioning on hepatic ischemia/reperfusion injury in the rat. Transplant Proc. 2007;39:361-4.

13. Lapenna G, Ciofani SD, Pierdomenico MA, Giamberardino F. Reaction conditions affecting the relationship between thiobarbituric acid reactivity and lipid peroxides in human plasma. Free Radic Biol Med. 2001;31(3):331-5.

14. Henry RJ, Chiamori N, Golub OJ, Berkman S. Revised spectrophotometric methods for the determination of glutamicoxalacetic transaminase, glutamic-pyruvic transaminase, and lactic dehydrogenase. Am J Clin Pathol. 1960;34:381-98.

15. Zamboni WA, Roth AC, Russell RC, Graham B, Suchy H, Kucan JO. Morphologic analysis of the microcirculation during reperfusion of ischemic skeletal muscle and the effect of hyperbaric oxygen. Plast Reconstr Surg. 1993;91(6):1110-23.

16. Jaeschke H. Mechanisms of reperfusion injury after warm ischemia of the liver. J Hepatobiliary Pancreat Surg. 1998;50:402-8.

17. Özden TA, Uzun H, Bohloli M, Toklu AS, Paksoy M, Simsek G, Durak H, Issever H, Ipek T. The effects of hyperbaric oxygen treatment on oxidant and antioxidants levels during liver regeneration in rats. Tohoku J Exp Med. 2004;203:253-65.

18. Tolentino EC, Castro-Silva O, Zucoloto S, Souza ME, Gomes MC, Sankarankutty AK, Oliveira GR, Feres O. Effect of hyperbaric oxygen on liver regeneration in a rat model. Transplant Proc. 2006;38:1947-52.
19. Baldim LB, Nejo Jr R, Souza ME, Gomes MC, Picinato MA, Fina $\mathrm{CF}$, Castro-e-Silva O. Effect of hyperbaric oxygen therapy on liver function during intermittent ischemia. Acta Cir Bras. 2013;28(1):61-5.

20. Ramachandran S, Liaw JM, Jia J, Glasgow SC, Liu W, Csontos K, Upadhya GA, Mohanakumar T, Chapman WC. Ischemiareperfusion injury in rat steatotic liver is dependent on NFKB P65 activation. Transpl Immunol. 2012;26:201-6.

21. Yu SY, Chiu JH, Yang SD, Yu HY, Hsieh CC, Chen PJ, Lui WY, Wu CW. Preconditioned hyperbaric oxygenation protects the liver against ischemia-reperfusion injury in rats. J Surg Res. 2005;128:28-36.

22. Lima CX, Sanches MD, Rezende Neto JB, Silva RC, Teixeira MM, Souza Dda G, Santos Gde C, Melo JR. Hyperbaric oxygen therapy aggravates liver reperfusion injury in rats. Acta Cir Bras. 2008;23(4):315-21.

23. Chaves JC, Fagundes DJ, Simões Mde J, Bertoletto PR, Oshima CT, Taha MO, Simões RS, Fagundes AL. Hyperbaric oxygen therapy protects the liver from apoptosis caused by ischemia-reperfusion injury in rats. Microsurgery. 2009;29(7):578-83.

24. Belghiti J, Noun R, Malafosse R, Jagot P, Sauvanet A, Pierangeli F, Marty J, Farges O. Continuous versus intermittent portal triad clamping for liver resection: a controlled study. Ann Surg. 1999;229:369-75.

\section{Correspondence:}

Orlando de Castro e Silva Jr

Departamento de Cirurgia e Anatomia

Faculdade de Medicina de Ribeirão Preto, USP

Campus Universitário

14049-990 Ribeirão Preto - SP Brasil

Tel.: (55 16)3632-4233

orlando@fmrp.usp.br

${ }^{1}$ Research performed at Liver Transplantation Unit, Department of Surgery and Anatomy, Faculty of Medicine of Ribeirao Preto, University of Sao Paulo (FMRP-USP), Ribeirao Preto-SP, Brazil. 